\title{
Omnichannel Retail and Business Model Transformation
}

\author{
Ioannis Allagiannis, Department of Informatics, Linnaeus University, Sweden \\ Aparna Lohiya, Department of Informatics, Linnaeus University, Sweden \\ Anita Mirijamdotter, Department of Informatics, Linnaeus University, Sweden
}

\begin{abstract}
Due to new technological developments and the ongoing digitalization, the traditional retail sector is currently exposed to major challenges. Digital Retail started with the development of e-commerce, when online companies, such as Amazon, began selling products online. These major online global players are still growing much faster than their smaller European retail competitors. As the absorption of buying power through online retailers, is dominated by global players based in Asia (Alibaba, Rakuten) and the United States (Amazon, eBay), Europe is experiencing a loss in revenue.

In this highly competitive market, traditional European brick-and-mortar retailers face hard challenges. However, studies show that most customers currently do not prefer pure online retailers, but a hybrid model, since traditional stores provide them with the opportunity to experience products and to receive personal advice from experts. This paper is a contribution to on-going research on the business model transition to include digital channels in traditional retail companies and to integrate various channels that support and streamline personal customer requirements. Thus, the paper explores challenges and opportunities for omnichannel management in the digital retail industry.
\end{abstract}

\section{Introduction}

The advent of technology has affected every industry in some way and retail is one of the industries that has been heavily affected by innovative digital technologies. These technologies have blurred the lines between physical and digital retail channels (Rigby, 2011; Hosseini et al., 2018). The last two decades have been instrumental in the transformation of the retail industry which was largely driven by the internet (Verhoef et al., 2015) and the emergence of other mobile technologies. It is not just that the traditional retailers are going online but the online retailers such as Amazon, Warby Parker, and Bononos, etc., are moving towards opening physical stores in the form of guide-shops and showrooms.

The use of electronic devices by consumers has increased, as mobile devices and internet data not just become more and more powerful but also cheaper. With this new turn of people in the use of mobile supercomputers in their hand in everyday life, there is a growth of electronic commerce and especially mobile commerce. Major global companies such as Amazon, eBay and Alibaba dominate the online global market, as they have listened early to changes in consumer habits and have invested in technologies that enhance the customer experience. The result is that they have already gained a large share of the world retail market and especially the European one. Conversely, traditional European Small and Medium Enterprises in the retail sector face hard challenges to be able to follow these rapid changes in the market and the competitive pressure is constantly growing.

The technology should not be an obstacle for traditional retailers, and nor should the small and medium retailers fear the perish in the hands of global online players, as it is not just the size of a firm that always matters but also how adaptive the firm is. Small and medium retailers have their own niche market with the presence of their physical stores and then with their online presence, they can reach a wider audience. In today's retail landscape, the transaction is not just about the buying and selling of goods and services, but it is about the whole customer journey from pre-purchase to purchase and to post-purchase. Therefore, business model transformation becomes the smart avenue for retailers to maximize the benefit for customers and retailers, both in this technology-driven era.

In addition, the recent economic recession and crisis due to the Pandemic caused by covid-19 worldwide have caused a big stagnation of markets, the real economic activity (Ashraf, 2020). Consumer activity in Retail has decreased especially for physical stores. The tourism and airline market has reached very low turnover levels 
worldwide. The stock market crash in 2020 brought about drastic changes in the world economy; even crude oil prices have collapsed (Baker et al., 2020). The global market is continuously in a changing mode. Therefore, from the abovementioned situation, European SMEs need to transform the way of doing business in order to survive in the global competition.

The Covid-19 pandemic has forced many retailers to go digital as most of the countries in Europe have been under lockdown for months. This situation has made the digitalization of retail even more urgent. During this shutdown, small and medium retailers who do not have an online presence suffered the most as all the shops and markets were closed for months. Shopping.at, an online platform launched by the Austrian Post, saw the number of visitors to their site almost quadrupled since the coronavirus measures were put in action. Both customers and retailers are equally showing interest in the online marketplace and this platform received requests for joining from hundreds of dealers. Some retailers made the move quicker than the others and opted to use third-party online platforms to sell their products and stay in the business, whereas others accelerated their own webshop planning and implementation.

The overall aim of this paper, as it is part of the Perform Project, which is funded by the European Union's Horizon 2020 research and innovation programme under the Marie Skłodowska-Curie grant, is to support European SME retailers to sustain their business by taking a step towards business model digitalization. By participating in this Programme, we aim to work towards suggestions and recommendations for SMEs in order for them to avoid adverse conditions in the European market. European SMEs constitute the backbone of the European economy and through this programme we focus on factors that may enable SMEs to develop innovative digital retail services and, in order to improve customer experience, offer omnichannel retail. The paper is part of ongoing research and in the following, we present preliminary literature reviews of concepts and models that guide our research, challenges, and opportunities for digital retail and for managing omnichannel business identified so far.

\section{Business Model}

The literature exposes a wide range of definitions of a business model (BM) that vary in scope and usage, however, most researchers agree that a business model expresses a firm's value creation, value proposition, and value capture mechanism (Osterwalder et al., 2005; Chesbrough, 2010; Zott and Amit, 2010; Golshan, 2018; Kurti, 2020). The Business Model is the most important factor, which describes the performance of a company (Afuah and Tucci, 2003). Business Model can be defined as the methods and activities practiced by a firm to make money. Reviews of business model literature reveal different schools of thought (Stubbs and Cocklin, 2008). The neoclassical economic theory is focused on maximizing profits for shareholders. The theory of Business Model Innovation (BMI) is focused on innovation and innovative products. The Sustainability business models (SBM) theories are focused on corporate sustainability. The Ecological Modernization (EM) model gives importance to the ecological dimensions, and so on.

Many studies focusing on Business Model notice different dimensions and different elements characterising a Business Model. The commonality for each notable, so-called, dimension, element, component, or building block (Afuah and Tucci, 2003; Osterwalder et al., 2005; Afuah 2019) is that these conform to the firm's business strategy, corporate resources, structure, relationships with customers, partners, suppliers, and corporate finance, and so on. Schallmo and Williams (2018) argues that combining all the Business Model elements strengthens the efficiency and the effectiveness of a Business Model. Another short definition of a Business Model is that a Business Model can be characterized as a "blueprint" (Osterwalder et al., 2005) of how to operate a firm. In short, the business model outlines how a firm creates value for customers in terms of better service and pricing, and how it appropriates value by improved inventory management or governance and structure. This gives a clear picture of sources of value creation and competitive advantage, which provides opportunities to update and strengthen the business model (Sorescu et al., 2011).

Digital technology and business model play an instrumental role in the retail industry's transformation towards seamless omnichannel retail (Hosseini et al., 2018; Jocevski et al., 2019). However, there is still a lack of guidance in the academic literature that would help researchers and practitioners to understand and evaluate the complex journey. The current literature mainly focuses on logistics and the supply chain (Aktas et al., 2020; Davis-Sramek et al., 2020). Retailers primarily sell products created by manufacturers and this alone could rarely provide them a sustainable competitive advantage as the manufacturer may create similar products for other retailers as well and similar products are readily available in the market. Focusing just on the product assortment will not take the retailer a long way so a successful retail business model should focus not only on what a firm sells but, more importantly, it should focus on how the firm sells (Sorescu et al., 2011). With smartphone and internet availability the product search and price information are available at fingertips as the shopper could simply search a product on the internet to see who sells it and at what price. So the product in itself or the pricing is not a winning strategy, 
a retailer can thrive and survive only when they improve the overall customer journey and provide a seamless purchase. As omnichannel is all about experiential shopping it is high time where retailers accept and utilize the technology to their advantage. Investing in ever-changing technology could be a huge obstacle especially for small and medium retailers but they may not need to invest all in the latest and most expensive technology, but they can just revise and redesign their business model to serve their customer in the best possible way without indulging in expensive in-store technologies.

\section{Changes in a Firm's Business Model and Key Challenges}

Four different types of changes in a firm's Business Model can be performed (Cavalcante et al., 2011), see Figure 1. The first type refers to the creation of a new Business Model where new business processes are created from the beginning of the formulation of the Business Model. The second type is the extension of an existing Business Model where new business processes are added to the existing ones. The third type is the revision of an existing Business Model, where existing business processes are revised. Finally, the fourth type refers to the termination of an existing Business Model in case that a Business Model is not the appropriate one for a specific time period.

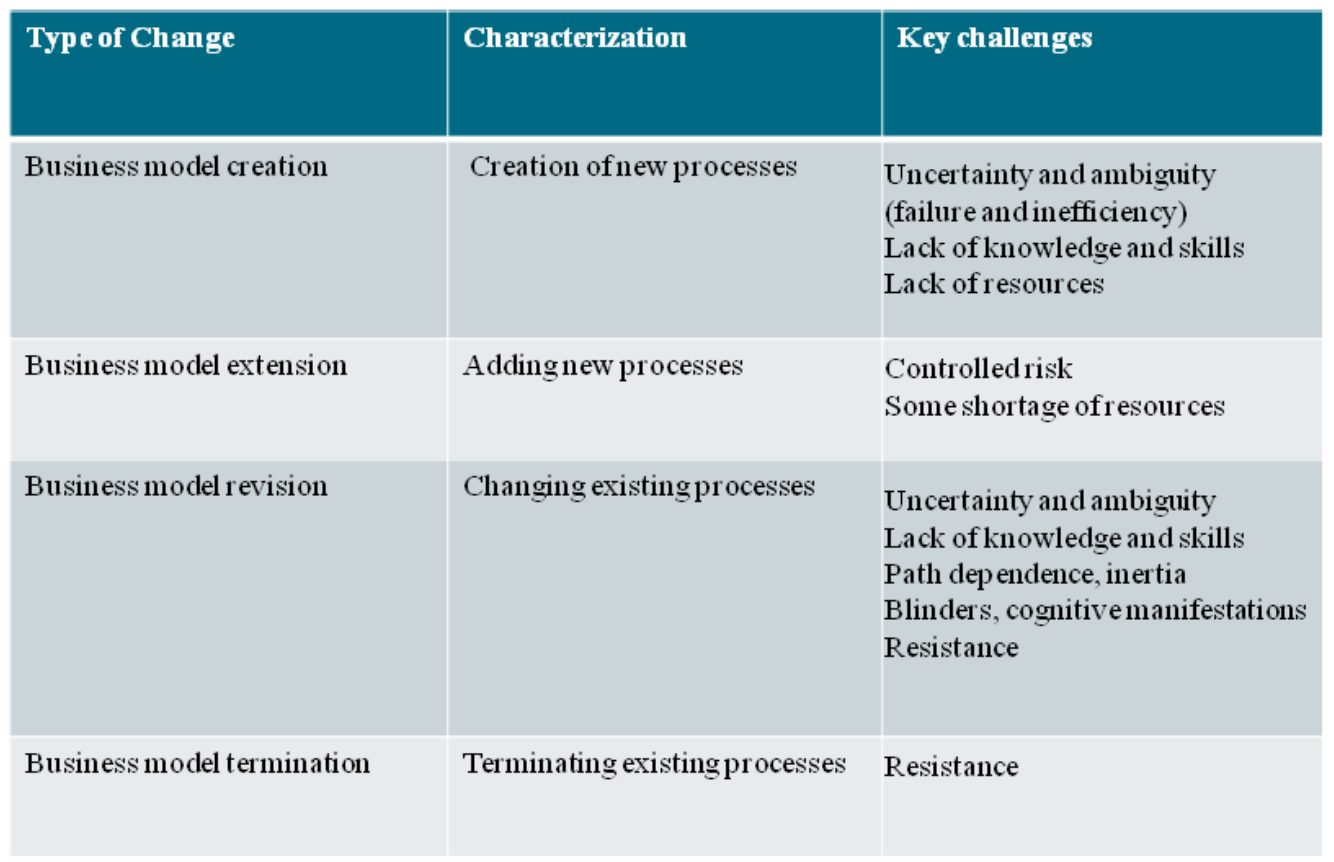

Figure 1. Changes in a Firm's Business Model and Key Challenges. Adopted by Cavalcante et al. (2011, p. 1334)

Furthermore, the most important key challenges during the creation of new processes in the business model, are the uncertainty and ambiguity in terms of failure and inefficiency, the lack of knowledge, and skills and the lack of corporate resources (Cavalcante et al., 2011). During the process of business model extension, which means that a company wants to add new processes, the most important challenges are the controlled risk and some possible shortage of resources. Next, during the business model revision, where a company wants to change the existing processes, the most important key challenges are the uncertainty and ambiguity, the lack of knowledge and skills, the path dependence, inertia, blinders, cognitive manifestations, and resistance of employees. Finally, during the phase of business model termination, where existing processes are to be terminated, the most important challenge found is the resistance of staff. Therefore by changing a firm's business model, it needs to be a transition process. Thus, changes cannot be done without planning for a transformation process, which will be elaborated on next. 


\section{Digital Transformation of Business Models}

In Figure 2 we illustrate common steps identified by Schallmo et al. (2017), Schallmo and Williams (2018) for transforming brick and mortar organizations towards digitalization of the business model, they presented a roadmap for digital transformation which is based on existing theories on business model innovation.

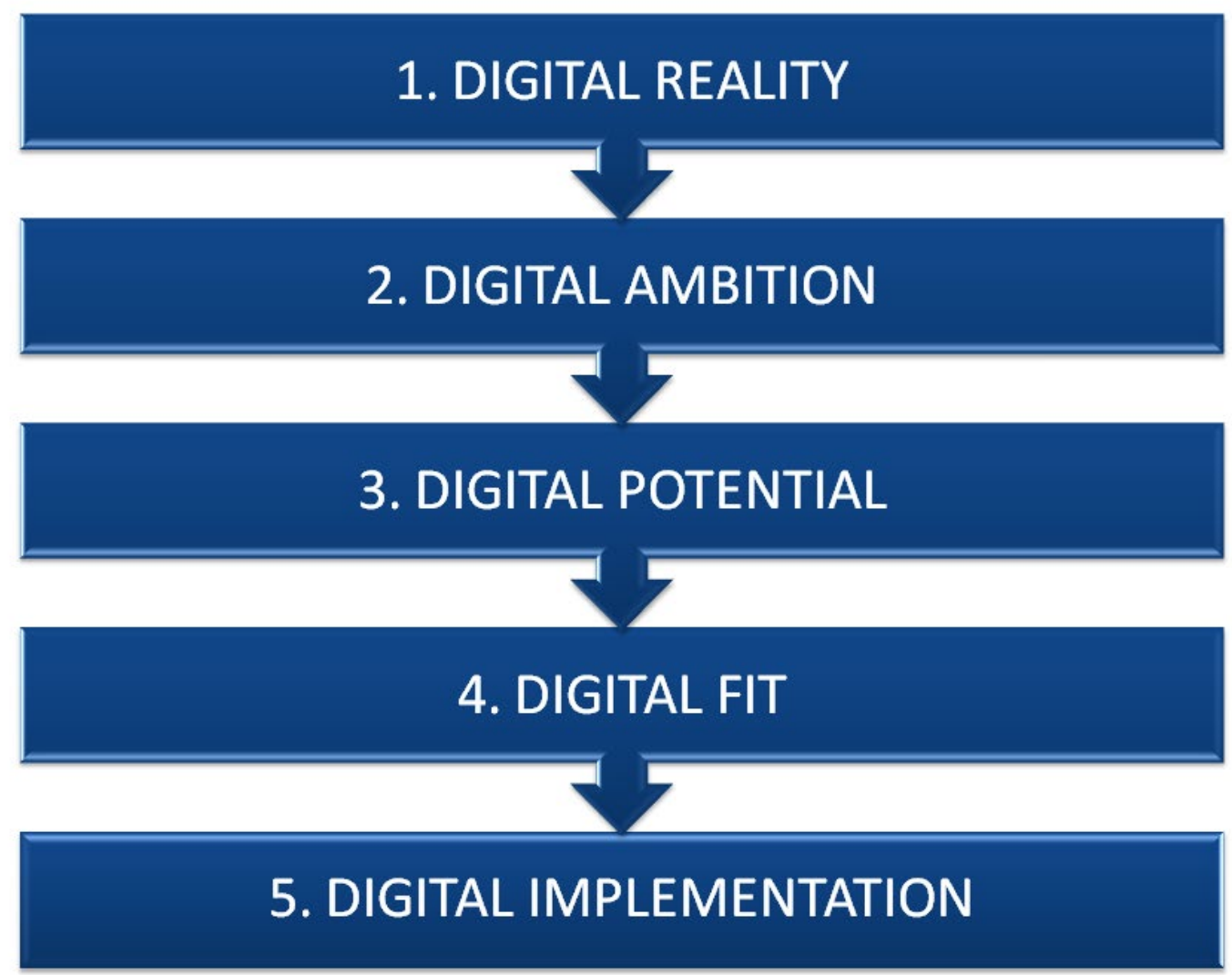

Figure 2. Roadmap to digital transformation. Adopted by Schallmo et al $(2017 ; \mathrm{p.8})$ and Schallmo and -Williams (2018, p.42)

The Roadmap to the digital transformation of business models, which a company can follow, starts from the stage referred to as digital reality. In this stage, Schallmo and Williams (2018) suggest that the existing Business Model should roughly be depicted, analysis should be made of value-creation related to stakeholders, and data be collected concerning customer requirements. The purpose of this stage is to gain an understanding of the digital reality for the company in various areas.

The second stage is called digital ambition where a firm has to set the corporate objectives for digital transformation in terms of time, finances, and quality and also prioritize the objectives according to the various BM dimensions.

The third stage is termed digital potential. In this stage, there should be a collection of best practices for the upcoming digital transformation identified and recognized, including what can be valid enablers for the transformation. The third stage should result in different options identified and related to and logically combined with the BM elements.

In the fourth stage, digital fit, the options are evaluated to settle that the firm fulfills customer requirements and corporate objectives, including other elements of the existing business model.

Finally, in the fifth stage of digital transformation, which is called digital implementation, the finalization and implementation of the digital transformation take place. In this stage, there is a need of designing the digital customer experience and the digital value-creation, which also involves network and corporate partnerships. 
Many tools and theories can be helpful for any retailer to make an audit and check the status during the process of the digital transformation. In an appendix, we list some useful tools and theories together with references, for assessing the status of digitalization according to the above figure. These can be used separately or in combination.

\section{Challenges Identified among Retailers}

In the above, we have presented some challenges as reported in the literature. In addition, our research so far has revealed some challenges as experienced by retailers in transforming to digitalization and omnichannel businesses. These challenges we report have been identified by seven interviews with business owners of SMEs in Greece. These interviews were performed on-site and concern retail stores selling both products and services and with varying degrees of internet presence. The interviews were conversational and semi-structured, based on the Business model dimensions of Afuah and Tucci (2003) and the SOG-e model of e-business maturity (McKay et al., 2000). The Afuah and Tucci (2003) BM includes profit site, customer value, scope, price, revenue sources, capabilities, sustainability, cost structure, implementation. It was used to structure the discussion concerning the firm business model. The SOG-e model was used to discuss with the respondents the various stages of digital maturity in the respective organization and also how digital technologies are integrated in a seamless fashion to the business model. The model includes six stages, which illustrate various levels of digital maturity. These range from no presence related to digital business to full integration of digital technology in internal processes as well as externally with business partners or in the network. The respondents found these models very interesting and beneficial for self-assessing their business model and their organizational digital maturity. The models also gave rise to discussions of issues, mainly in the form of challenges. Below we present some of the perceived challenges that the interviewees experienced when aiming to transform to digital business in general.

Lack of funding, that is, insufficient funding available to invest in digital technologies and in the transition. Evidence showed that the costs for moving from a physical store to a digital one are not low. Also, an omnichannel transition needs an optimum allocation of corporate resources so that the customer service does not face problems. Furthermore, the supply of products by suppliers, the shipment of goods from the store to consumers, the whole process, has to be planned and carried out without problems and delays. A retail brick-and-mortar store needs to allocate funds and resources, both tangible and intangible, in order to invest in digital business operations and to seamlessly manage omnichannel business operations.

Many times the lack of tradition in using computer-based ERP or CRM systems basically from small brick-andmortar retail stores, also indicate a lack of competence. Further, some retailers also have an inconsistency between IT systems, which is a big issue when they also have to add new business processes, new systems, at least a new online ordering and online payment system.

Digital transformation needs substantial changes in the well-known way to perform the work because much of the day-to-day work requires digital staff engagement. For example, customers will order online and all this work is done digitally. Their payments, as well and the largest number of communications, require digital communication channels. On top of that, a fear of online fraud and how to manage online transactions, in addition to the high costs for bank charges for online payments, constitute a challenge that adds more challenges in daily transactions with customers.

Among other things, the legislation enables all consumers to have the right to return products purchased online. Even the return of products which seems logical to happen requires on the part of the company corresponding actions to be taken, additional procedures and functions, new collaborations with transport companies and so on.

\section{Discussion}

Recognizing the potential of a well-formulated Business Model for a firm, we argue that a Business Model can ensure organization survival and excellence. Especially in times when the business survival of small and medium enterprises is threatened, the involvement of the corporate management to support the appropriate changes in the Business Model is considered necessary. Regardless of the many theories of Business Models and the different schools of thought that have been already mentioned (Afuah and Tucci, 2003; Osterwalder et al., 2005; Afuah 2019), digital transformation in the retail sector, seems to be one of the most important paths to be followed by retailers for their survival. In addition, this can be supported by the fact that although there are several periods of economic downturn, some companies succeed despite the existing challenges. But what exactly do businesses do in such circumstances, is to adapt to the new market conditions, in what customers ask for, in what help they can get from technology, in which competencies can be better, and which market gap they can fill.

Cavalcante et al., (2011), argues that the most important key challenges during changes in a Business Model are uncertainty and ambiguity in terms of failure and inefficiency. This argument really recognizes the business risks during corporate transformation, with extra challenges such as the lack of knowledge and skills and the lack of 
corporate resources. However, digital transformation is not a fast process done in one day; neither e-business maturity can be obtained in a short time, as illustrated in the Road map model (Schallmo et al., 2017; Schallmo and Williams, 2018). Based on the interviews performed, the maturity according to the SOG-e model (McKay et al., 2000), of the respective SMEs have been identified and validated among the respondents.

The retailers face not just the challenges related to technology but one of the major challenges is organizational related; the silo-ed mentality and conflict among personnel. So revamping the organization in terms of training staff, hiring new talents, and reallocation of resources across channels. In order to avoid conflict between online and offline channels, it is important for retailers to work as omnichannel and have a redesigned incentive system as well to encourage managers and employees to serve the customers irrespective of the channel choice (Cao, 2014).

Furthermore, the main driver behind the digitalization of retail towards omnichannel is the changing behavior of the consumers. The consumers are already omnishoppers who are online more and more, and this characteristic is recognized and confirmed in periods of lockdown due to the pandemic of covid-19 (Bhatti et al., 2020), so far. Access to cheaper internet data and smartphones has changed the way customers shop. Webrooming and showrooming have become a trend (Kang, 2018). Customers not just webroom and showroom but social media also influences their buying decisions, as reviews and ratings serve as huge influences. Thus, the changes in the e-commerce landscape foretell a major shift towards retail digitalization, where brick-and-mortar retailers need to adapt their offered value to their customers. There is no time for inertia as far as the retail landscape shows signs of a big decline due to pandemic circumstances.

\section{Conclusion}

In terms of academic contribution, we aim to provide some new insights into the field of business management and information systems. We aim to enrich the existing knowledge of the digital retail business model and business model transformation moving towards omnichannel. This paper will be helpful for the small and medium retailers who are moving towards digitalization. Adaptation through digital transformation is probably the new horizon of small and medium sized brick-and-mortar retailers. Although the challenges identified among retailers, the digital transformation of Business Models is a key to an espousal of a new way of doing business. The digital divide found in brick-and-mortar retailers can be eliminated by understanding the needs of the market, the new consumer behavior, and the influence of technology in our lives. Digitalization needs investments, however, the return will be great if a digital business model is designed correctly.

Retailers seem to need a motivation to perform a digital transformation, although the generation of a new Business Model or a change of an existing Business Model is not an easy task. Many challenges found that affect the transition decision towards digital transformation, as far as Business Model components identified, and corporate management elaborate on them, by exploring alternatives that may be beneficial. Business Model audit and diagnosis through theories presented in this paper along with the identification of digital maturity status, found that these are beneficial in planning for the future. According to the so-called Roadmap to digital transformation, by following the above mentioned recommendations, the process can be easier for retailers to transform their companies to omnichannel business.

As presented in the above, there are models and theories that we have begun to utilize and evaluate through applying these in practice. In forthcoming papers, we continue to build on these and report our findings.

Acknowledgement. This research received funding from the European Union's Horizon 2020 research and innovation programme under the Marie Skłodowska-Curie grant agreement No. 765395.

\section{References}

Afuah, A. and Tucci, C.L., 2003. Internet business models and strategies: Text and cases. New York: McGrawHill.

Afuah, A., 2019. Business model innovation: concepts, analysis, and cases. London: Routledge.

Aktas, E., Bourlakis, M. and Zissis, D., 2020. Collaboration in the last mile: evidence from grocery deliveries. International Journal of Logistics Research and Applications. https://doi.org/10.1080/13675567.2020.1740660

Ashraf, B.N., 2020. Stock markets' reaction to COVID-19: Cases or fatalities? Research in International Business and Finance, 54(101249). https://doi.org/10.1016/j.ribaf.2020.101249 
Baker, S.R., Bloom, N., Davis, S. J., Kost, K., Sammon, M. and Viratyosin, T., 2020. The unprecedented stock market reaction to COVID-19. The Review of Asset Pricing Studies, 10(4), pp. 742-758. https://doi.org/10.1093/rapstu/raaa008

Baker, S.R., Bloom, N., Davis, S.J. and Terry, S.J 2020. Covid-induced economic uncertainty. National Bureau of Economic Research. Working paper 26983. https://doi.org/10.3386/w26983 .

Bhatti, A., Akram, H., Basit, H.M., Khan, A.U., Raza, S.M., and Naqvi, M.B., 2020. E-commerce trends during COVID-19 Pandemic. International Journal of Future Generation Communication and Networking, 13(2), pp. 1449-1452.

Cao, L., 2014. Business model transformation in moving to a cross-channel retail strategy: A case study. International Journal of Electronic Commerce, 18(4), pp. 69-96. https://doi.org/10.2753/JEC10864415180403 .

Cavalcante, S., Kesting, P. and Ulhøi, J., 2011. Business model dynamics and innovation: (re)establishing the missing linkages. Management decision, 49(8), pp. 1327-1342. https://doi.org/10.1108/00251741111163142

Chesbrough, H., 2010. Business model innovation: Opportunities and barriers. Long Range Planning, 43(2-3), pp. 354-363. https://doi.org/10.1016/j.1rp.2009.07.010 .

Davis-Sramek, B., Ishfaq, R., Gibson, B. J. and Defee, C., 2020. Examining retail business model transformation: a longitudinal study of the transition to omnichannel order fulfillment. International Journal of Physical Distribution and Logistics Management, 50(5), pp. 557-576. https://doi.org/10.1108/IJPDLM-02-2019-0055

Golshan, B., 2018. Digital Capability and Business Model Reconfiguration: a co-evolutionary perspective. Licentiate Diss. Linnaeus University. http://urn.kb.se/resolve?urn=urn:nbn:se:Inu:diva-75177

Hosseini, S., RÃ glinger, M. and Schmied, F., 2018. Omni-Channel Retail Capabilities: An Information Systems Perspective. ICIS 2017: Transforming Society with Digital Innovation, 4801.

Jocevski, M., Arvidsson, N., Miragliotta, G., Ghezzi, A. and Mangiaracina, R., 2019. Transitions towards omnichannel retailing strategies: a business model perspective. International Journal of Retail and Distribution Management, 47(2), pp. 78-93. https://doi.org/10.1108/IJRDM-08-2018-0176 .

Kang, Ju-Young M., 2018. Showrooming, Webrooming, and User-Generated Content Creation in the Omnichannel Era. Journal of Internet Commerce, 17(2), pp. 145-169. https://doi.org/10.1080/15332861.2018.1433907

Kurti, E., 2020. Institutional Tensions and Complexity in the Digital Innovation of Incumbent Business Models. Doctoral Diss. Linnaeus University. http://urn.kb.se/resolve?urn=urn:nbn:se:lnu:diva-98707

McKay, J., Marshall, P. and Prananto, A., 2000. Stages of maturity for e-business: the SOG-e model. In: Pacific Asia Conference of Information Systems (PACIS), 2000, 3. Hong Cong, China, 1-3 June 2000. AISeL. http://aisel.aisnet.org/pacis2000/3

Osterwalder, A., Pigneur, Y. and Tucci, C. L., 2005. Clarifying Business Models: Origins, Present, and Future of the Concept. Communications of the Association for Information Systems, 16, pp. 1-25. https://doi.org/10.17705/1CAIS.01601

Osterwalder, A. and Pigneur, Y., 2010. Business model generation: A handbook for visionaries, game changers, and challengers. New Jersey: Wiley and Sons.

Pateli, A., 2003. A framework for understanding and analysing ebusiness models. In: Bled Electronic Commerce Conference, 2003, 4. 9-11 June, 2003. AISeL. https://aisel.aisnet.org/bled2003/4 .

Phan, D.H.B. and Narayan, P.K., 2020. Country responses and the reaction of the stock market to COVID-19A preliminary exposition. Emerging Markets Finance and Trade, 56(10), pp. 2138-2150. https://doi.org/10.1080/1540496X.2020.1784719

Rigby, D.K., 2011. The future of shopping. Harvard Business Review, 89(12), pp. 65-76.

Schallmo, D., Williams, C.A. and Boardman, L., 2017. Digital transformation of business models-best practice, enablers, and roadmap. International Journal of Innovation Management, 21(8), pp. 1-17. https://doi.org/10.1142/S136391961740014X.

Schallmo, D. and Williams, C., 2018. Digital Transformation Now! Guiding the Successful Digitalization of Your Business Model. Switzerland: Springer.

Sorescu, A., Frambach, R.T., Singh, J., Rangaswamy, A. and Bridges, C., 2011. Innovations in retail business models. Journal of Retailing, 87 (SUPPL. $\quad 1), \quad$ pp. $\quad$ S3-S16. https://doi.org/10.1016/j.jretai.2011.04.005.

Stubbs, W. and Cocklin, C., 2008. Conceptualizing a "sustainability business model". Organization and environment, 21(2), pp. 103-127 https://doi.org/10.1177/1086026608318042.

Verhoef, P.C., Kannan, P.K. and Inman, J.J., 2015. From Multi-Channel Retailing to Omni-Channel Retailing. Introduction to the Special Issue on Multi-Channel Retailing. Journal of Retailing, 91(2), pp. 174-181. https://doi.org/10.1016/j.jretai.2015.02.005.

Westerman, G., Bonnet, D. and McAfee, A., 2014. Leading digital: Turning technology into business transformation. Boston, Massachusetts: Harvard Business Review Press. 
Zott, C. and Amit, R., 2010. Business model design: An activity system perspective. Long Range Planning, 43(23), pp. 216-226. https://doi.org/10.1016/j.1rp.2009.07.004. 
Appendix: Tools and theories for assessing status of digitalization

- 3 levels for Measuring firm performance: profitability, profitability prediction, BM component attributes (Afuah and Tucci, 2003)

- Balance score card (Financial, Customer, Internet Business Perspective, Innovation and Learning) (Niven, P. 2002)

- CSF (Critical Success Factors) (Trkman, P, 2010)

- Porter's 5 forces framework (Competition in the industry, Potential of new entrants, The power of suppliers, The power of customers, The threat of substitute products) (Porter, 1980)

- Accounting and Economics - Current and Previous Year Profitability, PandL, Balance Sheet (Conclusions can be drawn from the financial data of the company by the comparison of current and previous year economics)

- KPI's (Key Performance Indicators) (Mar, B., 2012)

- Theories of Organizational Adaptation (Wheelen et al., 2018)

- Organizational Life Cycle Dominant Issue (Birth, Growth, Maturity, Decline, Death) (Wheelen et al., 2018)

- Strategic Planning Information Systems (Peppard and Ward, 2016)

- 4 Levels of Digital Mastery Beginners, Conservatives, Fashionistas, Digital Masters (Westerman et al, 2014)

- TOE Model (Technology, Organization, Environment. This model can help companies to understand the factors that affect the adoption of new technologies) (Allagiannis, 2004)

- CMMI (Capability Maturity Model Integration) (Team, C, 2006)

- SOG-e Model (Stages of Growth Model which can provide insights about eMaturity) (McKay, Marshall and Prananto, 2000)

- SWOT Analysis (Strengths, Weaknesses, Opportunities, Threats) (Piercy and Giles 1989; Wheelen et al., 2018)

- PEST analysis (Political, Economic, Social, Technological) (Ho, J.K.K., 2014)

\section{References for the appendix}

Afuah, A. and Tucci, C. L. 2003. Internet business models and strategies: Text and cases (Vol. 2), New York: McGraw-Hill.

Allagiannis I. 2014. EDI and Greek SMEs. A multiple case study in the context of technology, environment and organization. Master Diss. Linnaeus University Press. http://urn.kb.se/resolve?urn=urn:nbn:se:lnu:diva$\underline{35799}$

Ho, J. K. K., 2014. Formulation of a systemic PEST analysis for strategic analysis. European academic research, 2(5), 6478-6492.

McKay, J. Marshall, P, and Prananto, A., 2000. Stages of maturity for e-business: the SOG-e model, PACIS 2000 proceedings, 3. http://aisel.aisnet.org/pacis2000/3

Marr, B., 2012. Key Performance Indicators (KPI): The 75 measures every manager needs to know, Pearson UK.

Piercy, N. and Giles, W., 1989. Making SWOT analysis work, Marketing Intelligence and Planning, 7(5/6): 5-7. https://doi.org/10.1108/EUM0000000001042

Niven, P. R. 2002. Balanced scorecard step-by-step: Maximizing performance and maintaining results, John Wiley and Sons.

Porter, M. E., 1998. Competitive Strategy Techniques for analyzing industries and competitors, with a new introduction, New York, The Free Press.

CMMI Product Team, 2006. CMMI for Development, version 1.2. Software Engineering Institute. https://doi.org/10.1184/R1/6572327.v1

Trkman, P, 2010. The critical success factors of business process management. International journal of information management, 30(2), 125-134. https://doi.org/10.1016/j.ijinfomgt.2009.07.003

Peppard, J., and Ward, J. ( 2016). The strategic management of information systems: Building a digital strategy, 4th ed. Chichester: John Wiley and Sons, Ltd.

Westerman, G., Bonnet, D., and McAfee, A. 2014. Leading digital: Turning technology into business transformation, Harvard Business Press.

Wheelen, T. L., Hunger, J. D., Hoffman, A. N., and Bamford, C. E., 2017. Concepts in strategic management and business policy: Globalization, innovation and sustainability, Fifteenth Edition, Pearson. 